\title{
VISÃO SISTÊMICA (E PARALELA) DOS TRÂMITES PROCEDIMENTAIS DOS PROCESSOS ADMINISTRATIVOS DISCIPLINAR E DE RESPONSABILIZAÇÃO DE PESSOA JURÍDICA, AMBOS DO PODER EXECUTIVO DE MINAS GERAIS
}

\author{
SYSTEMIC (AND PARALLEL) VIEW OF THE PROCEDURAL \\ PROCEDURES OF THE ADMINISTRATIVE DISCIPLINARY \\ PROCESSES AND ACCOUNTABILITY OF LEGAL ENTITY, \\ BOTH OF THE EXECUTIVE POWER OF MINAS GERAIS
}

GLÁUCIA Milagre MENEZES ${ }^{1}$

MARCELO BARROSO LIMA BRITO DE CAMPOS ${ }^{2}$

\section{RESUMO}

O objetivo do presente artigo é apresentar os aspectos processuais no que tange o Processo Administrativo Disciplinar e o Processo Administrativo de Responsabilização de Pessoa Jurídica, este oriundo da Lei

1 Mestre em Direito no curso Instituições Sociais, Direito e Democracia, linha de pesquisa em Direito Público, pela Universidade FUMEC. Possui pós-graduação em Direitos Público e Privado e graduação em Direito, este pela Pontifícia Universidade Católica de Minas Gerais. Atualmente,é servidora pública no Governo do Estado de Minas Gerais/ Secretaria de Estado de Saúde de Minas Gerais e à disposição na Fundação Ezequiel Dias, na função de chefe do Núcleo de Correição Administrativa, da Controladoria Seccional.. ORCID iD: https://orcid.org/0000-0003-1674-8032. E-mail: glauciamilagre74@gmail.com.

2 Pós-doutorando em Direito Tributário pela Universidade Federal de Minas Gerais - UFMG (desde 2020). Doutor em Direito Público pela PUCMINAS (2011). Mestre em Administração Pública pela Escola de Governo Professor Paulo Neves de CarvaIho da Fundação João Pinheiro - MG (2002). Bacharel em Direito pela Universidade Federal de Minas Gerais - UFMG (1995). Professor de Direito Previdenciário, Direito Constitucional e Direito Tributário da Faculdade de Ciências Humanas, Sociais e da Saúde (FCH) da Universidade FUMEC, aonde é docente permanente da Graduação (desde 2018) e do Programa de Pós-Graduação Stricto Sensu em Direito (PPGD), desde 2020.. Professor de Direito Tributário, Direito Constitucional e Direito da Seguridade Social do Centro Universitário de Belo Horizonte - UNI-BH (desde 2002 em licença). Coordenador e professor do Curso de Pós-graduação lato sensu em Previdência do Servidor Público da Faculdade Arnaldo-IEPREV (2016/2020). Membro da Academia Brasileira de Direito da Seguridade Social - ABDSS. Procurador-Chefe da Procuradoria de Tributos e Assuntos Fiscais - PTF, da Advocacia-Geral do Estado de Minas Gerais (2015/2018). Procurador do Estado de Minas Gerais (desde 1998). Procurador-Chefe do Instituto de Previdência dos Servidores do Estado de Minas Gerais - IPSEMG (2003). Advogado (desde 1996). Diretor do Departamento de Direito Previdenciário do Instituto dos Advogados de Minas Gerais

Como citar esse artigo/How to cite this article:

MENEZES, Gláucia Milagre; CAMPOS, Marcelo Barroso Lima Brito de. Visão sistêmica (e paralela) dos trâmites procedimentais dos Processos Administrativos Disciplinar e de Responsabilização de Pessoa Jurídica, ambos do Poder Executivo de Minas Gerais. Revista Meritum, Belo Horizonte, vol. 15, n. 3, p.269-288, Set./Dez. 2020. DOI: https://doi.org/ 10.46560/meritum. v15i3.8315. 
Anticorrupção, ambos mineiros, com aspectos sancionadores e conduzidos pela Controladoria-Geral do Estado de Minas Gerais. São processos com finalidades específicas no âmbito do Poder Executivo Estadual, sendo que no primeiro tem por pressuposto apurar possíveis responsabilidades funcionais de servidor público mineiro e o segundo os atos lesivos praticados por pessoa jurídica. A intenção é realizar uma visão sistêmica e paralela entre os institutos, isto é, do Processo Administrativo Disciplinar mineiro, analisando conceitos e trâmites, com relação ao Processo Administrativo de Responsabilização de Pessoa Jurídica. A metodologia será a jurídica-dogmática, utilizando o método hipotético-dedutivo. Busca-se aprimorar o conhecimento do tema apresentado, fundamental no cumprimento de normas que devem ser conduzidas no viés de Estado Democrático de Direito, e que impõe em sede administrativa, tanto para servidores públicos que exercem trabalhos de corregedoria, bem como na posição de acusados, além de pessoa jurídica processada, inclusive para os respectivos advogados, quando em defesa técnica, o saber detido de tais processos sancionadores, para o melhor desempenho de cada função, em momento específico.

PALAVRAS-CHAVES: Processo Administrativo Disciplinar. Processo Administrativo de Responsabilização de Pessoa Jurídica. Estado Democrático de Direito. aprimoramento e Poder Executivo Estadual.

\section{SUMMARY}

The purpose of this article is to present the procedural aspects with respect to the Disciplinary Administrative Process and the Administrative Process for Accountability of Legal Entities, this originating from the Anticorruption Law, both from Minas Gerais, with sanctioning aspects and conducted by the Comptroller General of the State of Minas Gerais. These are processes with specific purposes within the scope of the State Executive Branch, with the former assuming to ascertain possible functional responsibilities of a civil servant in Minas Gerais and the latter the harmful acts practiced by legal entities. The intention is to realize a systemic and parallel vision between the institutes, that is, of the Minas Gerais Administrative Disciplinary Process, analyzing concepts and procedures, in relation to the Administrative Process of Accountability of Legal Entities. The methodology will be legal-dogmatic, using the hypothetical-deductive method. The aim is to improve the knowledge of the theme presented, which is fundamental in the fulfillment of rules that must be conducted under the bias of the Democratic State of Law, and which imposes in the administrative headquarters, both for public servants who carry out internal affairs work, as well as in the position of the accused. , in addition to the legal entity processed, including for the respective lawyers, when in technical defense, the knowledge held of such sanctioning processes, for the best performance of each function, at a specific time.

KEYWORDS: Disciplinary Administrative Process. Administrative Accountability Process for Legal Entities. Democratic state. improvement and State Executive Power.

\section{INTRODUÇÃO}

Este artigo propõe realizar uma breve análise dos trâmites processuais relativos ao processo administrativo disciplinar e processo de responsabilização de pessoa jurídica, esta oriunda da lei anticorrupção, ambos com execução no Poder Executivo de Minas Gerais.

- IAMG (2007/2018). Associado Benemérito e Conselheiro do Instituto Brasileiro de Direito Previdenciário - IBDP (desde 2006). Coordenador de Direito e Processo Previdenciário da Escola Superior de Advocacia da Ordem dos Advogados do Brasil, Seção Minas Gerais - ESA-OAB/MG (desde 2010).Membro da Comissão de Direito Previdenciário da OAB/MG (desde 2015). Membro titular do Conselho Fiscal da OABPrev-MG (desde 2015). Presidente do Conselho Deliberativo da PREVCOM-MG (desde 20148). Membro do corpo editorial da Revista Brasileira de Direito Previdenciário (desde 2011). Autor de livros com destaque para "Regime próprio de previdência social dos servidores públicos", Editora Juruá, 2017, 8a edição, "Manual dos Servidores Públicos: Administrativo e Previdenciário", Editora Lujur, 2020 e diversos artigos científicos. Lattes: http:// lattes.cnpq.br/1359289078163682. ORCID iD: https://orcid.org/0000-0002-2050-6653. E-mail: marcelo.brito@fumec.br. 
Para tanto, propõe-se estudo de cada instituto, apresentando conceitos e trâmites, mediante uma visão paralela entre ambos.

O método utilizado será o dedutivo, com base na pesquisa e na revisão bibliográfica, fundamentando-se em posições doutrinárias, institucionais e jurisprudenciais.

Na conclusão, procurar-se-á sintetizar a importância do conhecimento sistêmico de tais processos para o aprimoramento da atuação, seja do servidor ou do gestor, bem como do defensor de pessoa física ou jurídica que é acusada na esfera correcional em Minas Gerais.

\section{ASPECTOS PROCESSUAIS DO PROCESSO ADMINISTRATIVO DISCIPLINAR (PAD)}

O processo administrativo disciplinar é um processo acusatório, onde a Administração Pública detém a competência de apurar possíveis autoria e materialidade de irregularidade funcional.

Nenhuma penalidade disciplinar à servidores públicos mineiros poderá ser prescindida de processo administrativo disciplinar. Não é concebível à Administração Pública, mediante o Estado Democrático de Direito, impor medidas administrativas que irão propiciar consequências na vida funcional, sem que o servidor se manifeste ou se defenda previamente. Neste sentido, Sérgio Ferraz e Adilson Abreu Dallari:

A regra geral é a de que nenhuma decisão deve ser adotada sem o competente e adequado processo administrativo [...]. [...], tem múltiplas finalidades: garantir o respeito aos direitos das pessoas, melhorar o conteúdo das decisões administrativas, assegurar a eficácia das decisões, legitimar o exercícios das prerrogativas públicas, assegurar o correto desempenho das atividades administrativas, aproximar-se mais do ideal de justiça, diminuiir a distância entre a Administração e os cidadãos, sistematizar as ações administrativas, facilitar o controle da Administração e ensejar a efetiva aplicação dos princípios que regem a atividade administrativa. (FERRAZ; DALLARI, 2001, p. 121)

Conceitualmente, conforme os ensinamentos de José Armando da Costa, o PAD é "[...] a série de atos procedimentais ${ }^{3}$ que, formalizados em obdiência a certos rituas traçados pelas normas e outras fontes do Direito, se propõem a apurar a verdade real dos fatos [...]" . (COSTA, 2004, p.151)

Em outra obra, o mesmo autor afirma que:

No nosso Direito Disciplinar Positivo o processo disciplinar ordinário é o meio apuratório mais formal e exigente. Tal procedimento [...] é rigido pelos princípios constitucionais do devido processo legal, do contraditório, da ampla defesa e da dignidade humana, entre outros. (COSTA, 2008, p. 489)

3 Segundo André Cordeiro Leal: “Fazzalari, ao propor uma distinção lógica entre processo e procedimento (a partir do atributo do contraditório, característica que distingue processo e procedimento), desenvolve também uma teoria do provimento como a resultante da atuação do processo. Para a distinção que compreende, usa o contraditório como atributo especial do processo, atributo esse que permitiria traçar a linha demarcatória das características específicas do processo dentro do gênero procedimento. [...]" (LEAL, 2008, p. 113) 
Léo da Silva e Alves dispõe que: "O processo disciplinar, por sua vez, é o devido processo legal para examinar a responsabilidade do agente, a partir do cotejo entre a acusação e a defesa". (ALVES, 2004, p. 29)

Ainda o mencionado autor discorre que "[...] é o processo específico para aferir responsabilidade de servidor quanto contra ele foram recolhidas provas de ilícito funcional. [...]" (ALVES, 2012, p. 21)

Egberto Maia Luz esclarece que "[...] que se destina única e exclusivamente à apuração do desvio de conduta do servidor público [...]" (LUZ, 1999, p. 181)

De acordo com José dos Santos Carvalho Filho,

[...] é todo aquele que tenha por objeto a apuração de ilícito funcional e, quando for o caso, a aplicação da respectiva sanção, seja qual for a expressão adotada paa denominá-lo.

É este o processo administrativo litigioso, acusatório e definitivo que exige a incidência do princípio da ampla defesa e do contraditório, e do devido processo legal. Este, e somente este, é que, ao seu final, permite o administrador aplicar a penalidade adequada quando tiver sido efetivamente verificada a ocorrência de infração funcional. (CARVALHO FILHO, 2007, p. 850)

O poder-dever da instauração do processo administrativo disciplinar surge da imperatividade da observância de um conjunto de normas relativas a deveres e obrigações contidas no Estatuto de Servidor Público mineiro, a Lei Estadual de n869/52 (MINAS GERAIS, 1952), que impõe comportamentos positivos e abstenções, delimitando a conduta funcional dos servidores públicos em face a ordem jurídica vigente. 0 processo administrativo, inclusive o discilinar, está assegurado, ainda, no art. 41 , parágrafo $1^{\circ}$, inciso II da Constituição de $1988 .{ }^{4}$ (BRASIL, 1988)

Com relação a falta disciplinar é aquela em que o servidor público, no exercício de suas funções, por ação ou omissão exerce um comportamento funcional contrário ao que é exigido da atividade da Administração Pública.

Havendo a violação de condutas funcionais, é dever da autoridade conhecer do fato e tomar as providências para a sua apuração ${ }^{5}$, que poderá ainda surtir efeitos, eventualmente, de danos ao erário público. Neste sentido, o fim será confirmar a possível autoria, mediante a materialidade e a extensão do dano apresentados, se este último houver. Os efeitos poderão ocorrer no âmbito disciplinar (penalidade), com possível extensão no penal, quando caberá a autoridade máxima dar conhecimento ao Ministério Público, que avaliará seu recebimento. Reserva-se o ressarcimento do dano ao erário público ao âmbito da Tomada de Contas Especial, processo específico para esse fim ${ }^{6}$ e não o correcional, o que não impede do servidor processado assim o fazer em sede de PAD, por vontade espontânea, até mesmo para obter o benefício do TAD, se possível.

4 “II - mediante processo administrativo em que lhe seja assegurada ampla defesa; (Incluído pela Emenda Constitucional ${ }^{\circ}$ 19, de 1998) ". (BRASIL, 2020)

5 Art. 218 da Lei Estadual mineira de n 869/52, que assim dispõe: "A autoridade que tiver ciência ou notícia da ocorrência de irregularidades no serviço público é obrigado a promover-lhe a apuração imediata por meio de sumários, inquérito ou processo administrativo". (MINAS GERAIS, 2020)

6 Vide Manual de Tomada de Contas Especial, da Controladoria-Geral do Estado de Minas Gerais. Disponível em: http://cge. mg.gov.br/phocadownload/manuais_cartilhas/pdf/manual-de-tce.pdf. Acesso em: 09 mai. 2020. 
O processo administrativo disciplinar mineiro é realizado em três fases: a instauração, a instrução e o julgmento. A intenção é se ater ao PAD destinado ao servidor público civil, pois o militar tem regulamentação própria.

A instauração do processo administrativo disciplinar compete ao Chefe do Poder Executivo de acordo com o art. 83 da Constituição Estadual (MINAS GERAIS, 1989); ao Controlador-Geral do Estado de Minas Gerais, segundo o inciso IV do art. $2^{\circ}$ do Decreto $n^{\circ} 47.774$, de 03 de dezembro de 2019 (MINAS GERAIS, 2019); as autoridades máximas dos órgãos e entidades da Administração Pública Estadual, tendo em vista o art. 219 da Lei n 869/1952 (MINAS GERAIS, 1952), e aqueles que receberam delegação específica para o ato.

O processo, atualmente, é por meio do Sistema Eletrônico de Informações - SEIMG de acordo com o teor do Decreto Estadual de n 47.228, de 4 de agosto de 2017 (MINAS GERAIS, 2017), que dispõe sobre o uso e a gestão de documentos no âmbito do Poder Executivo de Minas Gerais.

Sendo o processo desenvolvido nas Entidades ou Órgãos da administração direta, encaminha-se respectivamente os documentos à Controladoria-Seccional ou Setorial, que viabilizará o encaminhamento ao respectivo Núcleo de Correição Administrativa (Nucad). Como já dito anteriormente, será elaborada a Avaliação Expediente (juízo de admissibilidade), a qual será direcionada ao titular do Órgão ou Entidade para despachar sobre a abertura do procedimento, que no caso em tela é o PAD. Nesse momento, além da avaliação quanto a correlação da prova inicial a possível irregularidade funcional, preocupa-se ainda verificar se o fato não esteja prescrito e sobre a existência de possível dano ao erário. Quanto a prescrição, é de suma importância conduzir a avaliação prévia sob esse enfoque, tendo em vista a observância do princípio da segurança jurídica. ${ }^{7}$

O Poder Disciplinar, como um dos poderes da Administração Pública, embora se afigure como prerrogativa da administração, deve amoldar-se às demais normas e princípios constantes do ordenamento jurídico em vigência, sendo imprescindível a sua observância em um Estado Democrático de Direito ${ }^{8}$.

Após essa decisão do titular do Órgão ou Entidade pela abertura do processo, o Nucad elaborará a minuta da Portaria, onde conterá três servidores efetivos, quando será indicado um que irá presidir os trabalhos, o nome do processado, a sua admissão, cargo exercido, Masp, conduta irregular (em tese) e a correlacionada disposição legal, e estipulando o prazo

7 A contagem do prazo inicia-se da ciência da autoridade máxima do Órgão ou Entidade, no Estado de Minas Gerais, de acordo com o art. 218 da Lei Estadual de n 869/52. Conforme o Manual de Apuração de llícitos da CGE/MG, a "[...] data do conhecimento dos fatos pela autoridade competente para instaurar o processo administrativo disciplinar. Tal posicionamento está consolidado no texto da Nota Técnica n 07/2015 [...]" (MINAS GERAIS, 2020, p.143). 0 prazo da prescrição será de acordo com a possível penalidade a ser aplicável: de dois anos e 150 dias para repreensão e suspensão; quatro anos e 150 dias para abandono de cargo e de cinco anos e 150 dias no caso de demissão e demissão a bem do serviço público. A sua arguição deverá ser pronunciada de ofício, sendo prescindível o requerimento por parte do interessado. São duas formas de prescrição: do conhecimento do fato até a publicação da portaria do PAD, quando se interrompe, ou seja, começa do zero (retroativa, exemplo, dois anos mais 150 dias, art.223 c/c art. 229 da Lei 869/52) e da instauração dos trabalhos pela publicação da portaria inaugural até a conclusão (intercorrente, exemplo, dois anos e 150 dias, art.223 c/c art. 229 da Lei 869/52). Esse controle serve também para a sindicância. Nos termos da Constituição de 1988, art. 37 , § $5^{\circ}$, o dano causado ao erário é imprescritível. 0 Estado de Minas Gerais segue esse entendimento.

8 Art. $5^{\circ}$, inciso LXXVIII, da CF: "a todos, no âmbito judicial e administrativo, são assegurados a razoável duração do processo e os meios que garantam a celeridade de sua tramitação. (Incluído pela Emenda Constitucional n 45, de 2004)" (BRASIL, 2020) 
inicial de sessenta dias para a sua conclusão, podendo ser prorrogado por mais trinta dias, de acordo com os artigos 221 e $223^{9}$ da Lei Estadual de nº 869/52. (MINAS GERAIS, 1952)

Providenciada a publicação do extrato da portaria inaugural do PAD, o chefe do Nucad providencia a atuação eletrônica do processo e o direciona à Comissão designada, no prazo de até três dias ${ }^{10}$ da publicação da portaria inaugural, conforme o art. 223 da Lei Estadual de n 869/52 (MINAS GERAIS, 1952).

Depois do recebimento do processo pela Comissão, haverá a designação do secretário (a) e a abertura dos trabalhos. Nesse momento, passa-se a fase da instrução.

Estando o processo em ordem, contendo todas as informações e provas que ensejaram a abertura da instrução, a Comissão irá citar ${ }^{11}$ o servidor processado, para que tenha conhecimento dos fatos a ele imputados, podendo designar advogado, apresentar defesa inicial, com documentos e rol de testemunhas, no prazo de dez dias, de acordo com o parágrado único do art. 224 da Lei Estadual de nº 869/52. (MINAS GERAIS, 1952)

A contagem do prazo será em dias corridos, quando se exclui o dia do começo e se inclui o do vencimento, prorrogando para o primeiro dia útil seguinte o prazo vencido em dia em que não haja expediente, tendo em vista o art. 280 da Lei Estadual n 869/1952. (MINAS GERAIS, 1952)

Sendo apresentada a defesa prévia, procuração do advogado, com o respectivo cadastro no Sistema Eletrônico de Dados - SEIMG, a Comissão procurará despacho sobre algum preliminar arguida, dando conhecimento ao servidor e respectivo advogado. Estando em ordem o processo, as oitivas dos depoimentos das testemunhas serão agendadas, ouvido primeiramente às solicitadas pela Comissão, se houver, e, posteriormente, as arroladas pelo servidor processado. Realizando todos os depoimentos necessários, do servidor processadoserá colhido o seu termo de declaração. Em todos esses procedimentos a presença do advogado é obrigatária, sendo facultada a do servidor apenas nos depoimentos das testemunhas.

Encerrada a instrução, a Comissão se reunirá para avaliar a instrução do processo, para se posicionar quanto a elaboração ou não do despacho de indiciamento, sendo que se emi-

9 A título de curiosidade, na portaria relativa à sindicância administrativa investigatória, poderá a comissão conter um ou mais servidores, não necessariamente estáveis, e com prazo inicial para a conclusão dos seus trabalhos de trinta dias, podendo ser prorrogado por mais trinta dias, segundo o art. 220, § $2^{\circ}$, da Lei Estadual n 869/1952. (MINAS GERAIS, 2020)

10 A extrapolação do prazo de autuação e da recondução dos trabalhos, além do estipulado na Lei Estadual de n 869/52, não acarretam a nulidade do processo. 0 importante é registrar a justificativa, caso ocorra.

11 “Na Lei Estadual n 869/1952, faz-se menção à revelia no art. 226, que dispõe, como já afirmado, que, no caso de revelia, "será designado, 'ex-ofício', pelo presidente da comissão, um funcionário para se incumbir da defesa". [...] .

[...]

Não se considera inepta a defesa apresentada por profissional inscrito na $\mathrm{OAB}$, uma vez que há uma presunção de que ela apresenta elementos mínimos para ser considerada uma defesa técnica.

[...]

Entende-se que, como a lei estadual é silente nessa questão, para se garantir o contraditório e a ampla defesa, adota-se o entendimento segundo o qual deve ser nomeado defensor dativo quando o acusado não apresenta defesa e, quando a apresenta, esta é considerada inepta.

[...]

Em resumo, não caberá a nomeação de defensor dativo ou ad hoc quando o acusado ou seu procurador tiverem sido devidamente intimados para o ato. Por uma questão de razoabilidade e para garantir o contraditório e a ampla defesa, caberá nomeação de defensor dativo para o acusado que não tiver condições técnicas e financeiras de se defender e nos casos em que a defesa é considerada inepta, desde que o acusado declare essa hipossuficiência nos autos [...]. [...]

Segundo entendimento da Corregedoria-Geral da CGE-MG no Manual de Apuração de llícitos Administrativos, para garantir a ampla defesa ao acusado, o defensor dativo deve ser, preferencialmente, bacharel em Direito, segundo entendimento expresso no Parecer da AGE n 15.409/2014. Exceto isso, não é exigida qualquer outra qualidade do defensor dativo face ao acusado, uma vez que não há exigência expressa na lei. [...]." (MINAS GERAIS, p. 293-297) 
tido, o servidor e o seu advogados serão intimados para ter dele conhecimento e apresentar a defesa final em dez dias, conforme a delimitação dos artigos imputados e as respectivas penalidades.

Recebida a defesa final, a Comissão avaliará os autos e elaborará o seu relatório conclusivo (final), de acordo com a integralidade do art. 127 da Lei Estadual mineira de $n^{\circ}$ 869/52 (MINAS GERAIS, 1952), sugerindo absolvição; arquivamento; penalidade, bem como providências que poderiam melhorar o serviço público vinculado ao objeto do PAD.

Seguirá os autos para o Núcleo de Correição Administrativa, que, juntamente com a Controladoria Setorial ou Seccional emitirá a Nota Técnica, com recomendações. Após tal procedimento, os autos será direcionado ao titular do Órgão ou Entidade, para decisão, em sessenta dias, de acordo com o art. 229 da Lei Estadual mineira de nº 869/52. (MINAS GERAIS, 1952)

A decisão poderá se fundamentar nas sugestões contidas no Relatório Final, nas recomendações da Nota Técnica, porém detém autonomia de divergir de ambas, com as suas razões quanto a legalidade e ao mérito administrativo, segundo o

[...] princípio do livre convencimento motivado, a autoridade julgadora pode divergir do relatório produzido pela comissão, caso o entenda contrário às provas produzidas. Neste caso, a autoridade pode, motivadamente, agravar a penalidade proposta, abrandá-la ou isentar o servidor de responsabilidade. (MINAS GERAIS, 2020 , p. 309)

A decisão será publicada na Imprensa Oficial de Minas Gerais, no prazo de oito dias, com vista no art. 231 da Lei Estadual mineira de n 869/52 (MINAS GERAIS, 1952). Quando houver aplicação de penalidade, poderá o servidor apresentar o seu Pedido de Reconsideração, no prazo de dez dias, que deverá ter sua decisão publicada também pela Imprensa Oficial de Minas Gerais.

A qualquer tempo pode-se requerer revisão do processo ao Governador de Estado, conforme art. 235 da Lei Estadual mineira de n 869/52, "[...] desde que se aduzam fatos ou circunstâncias susceptíveis de justificar a inocência do acusado." (MINAS GERAIS, 1952).

O assunto quanto ao trâmite processual é tão relevante quanto se saber como se ponderar na sugestão de penalidade a ser apresentada pela Comissão, no resultado final dos trabalhos.

Quando da elaboração do Relatório Final pela Comissão, o que se tem em mente é observar se os argumentos de defesa e as provas contidas nos autos podem desconstituir a autoria e a materialidade que, em tese, foram imputados ao servidor. No Estado Democrático de Direito é imprescindível o exercício dos princípios do contraditório e da ampla defesa, bem como da não surpresa, em processos administrativos disciplinares, dando a este último princípio especial atenção após o despacho de indiciamento.

Com o despacho de indiciamento, a Comissão avaliará a correlação da possível conduta irregular do servidor à conduta realizada, a qual poderá ser direcionada aos deveres, as obrigações e as proibições, conforme os artigos 216, 217, 246, 248, 249 e 250, todos da Lei Estadual mineira de $\mathrm{n}^{\circ} 869 / 52^{12}$, com a possíveis penalidades contidas nos artigos 244 e 
245, do mesmo corpo normativo, sendo que dessa individualização a defesa apresentará os argumentos finais. (MINAS GERAIS, 1952).

Feito isso, a sugestão do encerramento da demanda terá por norte verificar se as condutas ditas por irregularidades e imputadas no despacho de indiciamento são procedentes ou não, em conformidade com o conjunto probatório aferido até o encerramento da instrução e com os argumentos apresentados em defesa final.

As penalidades são aquelas dispostas no art. 244, observando no caso de repreensão ou suspensão a integralidade do art. 245, dispositivos contidos na Lei Estadual mineira de $\mathrm{n}^{\circ}$ $869 / 52$. Para tanto, será observada a gravidade da irregularidade; a da intenção do servidor acusado em realizá-la ou dos procedimentos que que ele operou que pudessem desconstitui-la; o histórico funcional do servidor, bem como se este é reincidente ${ }^{13} \mathrm{em}$ PAD e a questão do dano ao erário em decorrência dessa conduta, podendo ainda, ter consequências fora do âmbito administrativo, quando deverá ser sugerido à autoridade máxima a remessa das informações ao Ministério Público ou outro Órgão ou Entidade que possam ter interesse no conhecimento dos fatos. (MINAS GERAIS, 1952).

\section{ASPECTOS PROCESSUAIS DO PROCESSO DE RESPONSABILIZAÇÃO DE PESSOAS JURÍDICAS (PAR)}

No âmbito correcional, além dos processos administrativos disciplinares em desfavor dos servidores públicos, tem-se processos administrativos de responsabilização de pessoas jurídicas (PAR).

O Manual de llícitos Administrativos da Controladoria-Geral do Estado de Minas Gerais assim dispõe:

No âmbito de procedimentos disciplinares, que apuram ilícitos funcionais praticados por agentes públicos, pode-se, eventualmente, constatar a participação de pessoas jurídicas nas irregularidades. Dessa forma, no juízo de admissibilidade (análise preliminar) ou no curso de procedimentos disciplinares (sindicâncias administrativas, investigações preliminares e processos administrativos disciplinares), os servidores devem se atentar para o envol-

se achar necessário, ajustar a definição jurídica e alterar o enquadramento legal das condutas, julgando, inclusive, para agravar a penalidade a ser aplicada.

[...]

Portanto, considerando as provas constantes nos autos, admite-se que a autoridade julgadora decida em sentido diverso daquele apontado nas conclusões da comissão, desde que o faça motivadamente e de acordo com as provas constantes nos autos.

[...]." (MINAS GERAIS, 2020, p.310)

13 A reincidência termina com a adoção da reabilitação administrativa. 0 art. 253 da Lei Estadual mineira de $n^{\circ} 869 / 52$ assim dispõe: "[...]

$\S 2^{\circ}$ - O funcionário poderá requerer reabilitação administrativa, que consiste na retirada, dos registros funcionais, das anotações das penas de repreensão, multa, suspensão e destituição de função, observado o decurso de tempo assim estabelecido:

1 - três (3) anos para as penas de suspensão compreendidas entre sessenta (60) a noventa (90) dias ou destituição de função;

2 - dois (2) anos para as penas de suspensão compreendidas entre trinta (30) e sessenta (60) dias;

3 - um (1) ano para as penas de suspensão de um (1) a trinta (30) dias, repreensão ou multa. 
vimento desses entes privados nos atos ilícitos para recomendar e/ou promover os devidos encaminhamentos. (MINAS GERAIS, 2020, p. 321)

Por isso a importância de se estudar os normativos que tratam da matéria pertinente ao processo de responsabilização de pessoa jurídica ${ }^{14}$, mesmo atuando no âmbito correcional direcionado a servidores públicos mineiros.

A Lei Federal de $n^{0} 12.846$, de 01 de agosto de 2013, apresenta as diretrizes iniciais quanto à "responsabilização administrativa e civil de pessoas jurídicas pela prática de atos contra a administração pública, nacional ou estrangeira", com vistas à responsabilidade objetiva, tendo em vista o acontecimento dos atos lesivos elencados no seu art. $5^{015}$, podendo, ainda, por exceção, atingir os seus sócios de maneira subjetiva. São responsabilidades independentes (BRASIL, 2013).

Considerando o rol apresentando no mencionado artigo $5^{\circ}$, não existe a forma tentada ${ }^{16}$, bem como contém a denominação de agente público, administração pública estrangeira e a equiparação desta às organizações públicas internacionais ${ }^{17}$.

14 Conforme dispõe a CGE/MG, por meio da sua Corregedoria-Geral: "A Lei Anticorrupção Empresarial dispõe sobre a responsabilização administrativa e civil de pessoas jurídicas pela prática de atos contra a Administração Pública, nacional ou estrangeira. Sua promulgação representa um marco normativo de combate à corrupção e de proteção à moralidade administrativa, apresentando um novo paradigma na relação entre o setor público e o setor privado". (CGE/MG, 2020, p. 321)

15 Lei 12846/13, art. 50: "Constituem atos lesivos à administração pública, nacional ou estrangeira, para os fins desta Lei, todos aqueles praticados pelas pessoas jurídicas mencionadas no parágrafo único do art. $1^{\circ}$, que atentem contra o patrimônio público nacional ou estrangeiro, contra princípios da administração pública ou contra os compromissos internacionais assumidos pelo Brasil, assim definidos:

I - prometer, oferecer ou dar, direta ou indiretamente, vantagem indevida a agente público, ou a terceira pessoa a ele relacionada;

II - comprovadamente, financiar, custear, patrocinar ou de qualquer modo subvencionar a prática dos atos ilícitos previstos nesta Lei;

III - comprovadamente, utilizar-se de interposta pessoa física ou jurídica para ocultar ou dissimular seus reais interesses ou a identidade dos beneficiários dos atos praticados;

IV - no tocante a licitações e contratos:

a) frustrar ou fraudar, mediante ajuste, combinação ou qualquer outro expediente, o caráter competitivo de procedimento licitatório público;

b) impedir, perturbar ou fraudar a realização de qualquer ato de procedimento licitatório público;

c) afastar ou procurar afastar licitante, por meio de fraude ou oferecimento de vantagem de qualquer tipo;

d) fraudar licitação pública ou contrato dela decorrente;

e) criar, de modo fraudulento ou irregular, pessoa jurídica para participar de licitação pública ou celebrar contrato administrativo;

f) obter vantagem ou benefício indevido, de modo fraudulento, de modificações ou prorrogações de contratos celebrados com a administração pública, sem autorização em lei, no ato convocatório da licitação pública ou nos respectivos instrumentos contratuais; ou

g) manipular ou fraudar o equilíbrio econômico-financeiro dos contratos celebrados com a administração pública;

V - dificultar atividade de investigação ou fiscalização de órgãos, entidades ou agentes públicos, ou intervir em sua atuação, inclusive no âmbito das agências reguladoras e dos órgãos de fiscalização do sistema financeiro nacional.

[...]". (BRASIL, 2013)

16 Esclarecem José Anacleto Abduch Santos, Mateus Bertoncini, Ubirajara Custódio Filho: "A tentativa pode constituir fato típico administrativo, desde que expressamente previsto em lei. Os atos lesivos (fatos típicos) passíveis de sanção com base na Lei 12.846/2013 são aqueles arrolados exaustivamente no art. $5^{\circ}$. Não quis o legislador tipificar a tentativa. É de se concluir, então, que as infrações legalmente previstas não admitem a forma tentada. A norma contida no inc. III em análise atribui a possibilidade de atenuar ou de agravar a sanção consoante a infração tenha ou não sido consumada". (SANTOS, BERTONCINI e CUSTÓRIO FILHO, 2014, p.183)

17 Art. $5^{\circ}$ da Lei 12.846/13: "[...]. § $1^{\circ}$ Considera-se administração pública estrangeira os órgãos e entidades estatais ou representações diplomáticas de país estrangeiro, de qualquer nível ou esfera de governo, bem como as pessoas jurídicas controladas, direta ou indiretamente, pelo poder público de país estrangeiro.

$\S 2^{\circ}$ Para os efeitos desta Lei, equiparam-se à administração pública estrangeira as organizações públicas internacionais. $\S 3^{\circ}$ Considera-se agente público estrangeiro, para os fins desta Lei, quem, ainda que transitoriamente ou sem remuneração, exerça cargo, emprego ou função pública em órgãos, entidades estatais ou em representações diplomáticas de país estrangeiro, assim como em pessoas jurídicas controladas, direta ou indiretamente, pelo poder público de país estrangeiro ou em organizações públicas internacionais". 
É de se ressaltar que o combate à corrupção, nos termos da Lei Federal de $n^{\circ}$ 12846/13, não se restringe ao âmbito federativo, através da Controladoria-Geral da União ${ }^{18}$ (BRASIL. 2013). Segundo os autores Luiz Francisco Mota Santiago Filho e Louise Dias Portes, tendo por revisor Matheus Cunha,

E, de fato, a Lei nº 12.846/2013 não condiciona sua imediata aplicação à sua regulamentação, mas fazê-lo parece-nos uma providência essencial à segurança jurídica e à garantia do devido processo legal. No âmbito dos estados e municípios, a regulamentação faz-se necessária para fixar critérios de competência interna, tais como quais os órgãos responsáveis por investigar as infrações, aplicar as penalidades e negociar os acordos de leniência, bem como fixar critérios de dosimetria das sanções e as regras procedimentais (v.g. prazos, possibilidade de recursos, produção de provas etc.). Podem, ainda, estabelecer requisitos e parâmetros de avaliação de Programas de Integridade para atenuação de eventuais sanções. (SANTIAGO FILHO, PORTES, CUNHA, 2018, p.3)

No Estado de Minas Gerais, no âmbito do Poder Executivo Estadual, o assunto pertinente ao PAR foi regulamentado pelo Decreto Estadual n 46.782/2015 e trouxe em seu corpo normativo características que o define e procedimentaliza (MINAS GERAIS, 2015), conforme será discorrido a seguir.

Por fim, registra-se que na esfera da responsabilização da pessoa jurídica tem-se a Investigação Preliminar, que subsidiará a decisão do Controlador-Geral pela instauração do PAR ou arquivamento do expediente. Tem caráter sigiloso e não punitivo. Está normatizado através do art. $4^{\circ}$ do Decreto Estadual $n^{\circ}$ 46.782/2015. (MINAS GERAIS, 2015)

O Processo Administrativo de Responsabilização de Pessoas Jurídicas no âmbito mineiro está regrado no Decreto Estadual n 46.782/2015 ${ }^{19}$ (MINAS GERAIS, 2015), norma publicada na Imprensa Oficial em 24 de junho de 2015 e alterada pelo Decreto $n^{\circ} 47.752$, de 12/11/2019, em vigor a partir de 12/12/2019. (MINAS GERAIS, 2019).

O PAR tem por objeto apurar possíveis atos lesivos realizados por pessoa jurídica à Administração Pública Estadual, de acordo com as condutas descritas no art. $5^{\circ}$ da Lei 12.846/13 (BRASIL, 2013).

No âmbito do Poder Executivo, cabe a competência à Controladoria-Geral do Estado de Minas Gerais (CGE/MG), na autoridade máxima do Controlador-Geral, de acordo com art. $2^{\circ}$ do Decreto Estadual de $n^{\circ} 46782 / 15$ (MINAS GERAIS, 2015). Isto quer dizer que não cabem aos órgãos e nem tão pouco as entidades indiretas que integram o organismo estatal as tratativas quanto à matéria pertinente ao PAR.

18 Estados/normas que regulamentaram a execução da Lei 12846/13, dados colecionados até 29/01/2018: Tocantins: Decreto $n^{\circ}$ 4.954/2013; São Paulo: Decreto n 60.106/2014; Paraná: Decreto nº 10.271/2014; Goiás: Lei n 18.672/2014; Espírito Santo: Decreto n ${ }^{\circ}$ 3.727-R/201411; Rio Grande do Norte: Decreto n 25.177/2015; Minas Gerais: Decreto ${ }^{\circ}$ 46.782/2015; Maranhão: Decreto n 31.251/2015; Distrito Federal: Decreto n 37.296/2016; Mato Grosso: Decreto ${ }^{\circ}$ 522/2016; Alagoas: Decreto $n^{\circ}$ 48.326/2016; Mato Grosso do Sul: Decreto ${ }^{\circ}$ 14.890/2017; Santa Catarina: Decreto $n^{\circ}$ 1.106/2017; e Pernambuco: Lei $n^{\circ}$ 16.309/2018; Rio de Janeiro: Lei Estadual $n^{\circ}$ 7.753/2017 e Decreto $n^{\circ}$ 46.366/2018; Distrito Federal: Lei $n^{\circ}$ 6.112/2018. "Destaca-se que o estado do Amazonas, em que pese não ter regulamentado a Lei Anticorrupção no âmbito do poder executivo estadual, conta com uma resolução do Tribunal de Justiça12 que estabelece procedimentos regulatórios para sua execução e, no estado do Rio Grande do Sul, há um provimento do Procurador Geral da Justiça13 que regulamenta a Lei Anticorrupção no âmbito do Ministério Público". (FILHO; PORTES e CUNHA, 2018, p.4-5)

19 No seu artigo $1^{\circ}$ dispõe: "Art. $1^{\circ}$ Este Decreto regulamenta, no âmbito da Administração Pública do Poder Executivo Estadual, o Processo Administrativo de Responsabilização - PAR -, previsto no Capítulo IV da Lei Federal no 12.846 , de $1^{\circ}$ de agosto de 2013, que dispõe sobre a responsabilização administrativa e civil de pessoas jurídicas pela prática de atos contra a administração pública, nacional ou estrangeira." (MINAS GERAIS, 2015). 
O que ocorre é que, muitas das vezes, é possível em sede de SAI ou PAD verificar indícios de ocorrência de atos condizentes ao art. $5^{\circ}$ da Lei 12.846/13 (MINAS GERAIS, 2013). Ainda, é factível que o setor de Apuração de Irregularidade e Indicação de Penalidades em desfavor de alguma pessoa jurídica de um Órgão ou Entidade, quando na avaliação do procedimento, verifique o descumprimento de cláusula contratual que possa ensejar a ocorrência de atos correspondentes ao citado artigo da Lei Anticorrupção. Em ambos os casos, a matéria e respectivas evidências são direcionadas à CGE/MG.

No PAR compreende as seguintes fases: juízo de admissibilidade; instauração; instrução e julgamento.

Conforme o Decreto Estadual de $n^{\circ} 46782 / 15$, no seu art. $3^{\circ}$, o Controlador-Geral "ao tomar ciência da possível ocorrência de ato lesivo à Administração Pública Estadual, em sede de juízo de admissibilidade e mediante despacho fundamentado" (MINAS GERAIS, 2015) decidirá em dar continuidade às apurações, na modalidade de investigação preliminar, considerando que aquele fato exige maiores esclarecimentos; em instaurar o Processo Administrativo de Responsabilização (PAR) ou no arquivamento dos fatos analisados.

Dando continuidade ao estudo do Decreto Anticorrupção mineiro, no seu art. $4^{\circ}$ esclarece o que seja a investigação preliminar, que se destina a um procedimento sigiloso, não punitivo e com caráter investigativo, quando se determinará a materialidade e possível autoria. Considerando que se trata de um procedimento de natureza inquisitiva, inicialmente, é salutar que a autoria deva ser balizada em sede de contraditório e ampla defesa no PAR, em momento oportuno.

Nesse sentido, sendo possível indicar a materialidade e a possível autoria, a apuração que tem prazo legal de trinta dias $\left(\S 1^{\circ}\right.$ do art. $\left.4^{\circ}\right)$, "[...] serão enviadas ao Controlador-Geral do Estado as peças de informação obtidas, acompanhadas de relatório conclusivo acerca [...] de atos lesivos à Administração Pública Estadual, para decisão sobre a instauração do PAR" $\left(\S 2^{\circ}\right.$ do art. $4^{\circ}$ ) (MINAS GERAIS, 2015).

Na portaria de instauração constará de três servidores estáveis, sendo um deles indicado para presidir, sendo tal requisição de caráter irrecusável. Constará a menção ao nome do órgão ou entidade, os fatos que serão apurados, bem como o nome da pessoa jurídica e, se houver, o CNPJ da pessoa jurídica. Essa portaria é publicada integralmente e, no decorrer das apurações, se existirem os outros fatos não mencionados nela, poderão integrar a apuração sem necessidade de aditamento ou complementação do ato de instauração, desde que garantidos à ampla defesa e o contraditório. Tendo origem a portaria em acordo de leniência, tal fato será nela mencionado. Esses critérios estão estabelecidos no corpo do art. $5^{\circ}$ do Decreto Estadual de $n^{\circ}$ 46.782/15 (MINAS GERAIS, 2015).

Quando o Controlador-Geral "diante de indícios de graves prejuízos [...], poderá, cautelarmente e de forma fundamentada, determinar a suspensão de procedimentos licitatórios, contratos ou quaisquer atividades e atos administrativos relacionados ao objeto do PAR, até a sua conclusão", de acordo com o art. $6^{\circ}$ do Decreto Estadual de n 46782/15 (MINAS GERAIS, 2015).

Tendo a autoridade máxima do órgão ou entidade conhecimento de atos lesivos previstos no art. $5^{\circ}$ da Lei Federal n 12.846, de 2013 (BRASIL, 2013), por meio de denúncias, representações e ocorrências, deverá dar ciência desse acometimento à Controladoria-Geral 
do Estado, sendo que em caso de desobediência a esse comando, poderá estar sujeito a responsabilização civil, penal e administrativa, consoante 0 art. $7^{\circ}$ do Decreto Estadual de $\mathrm{n}^{\circ}$ 46782/15 (MINAS GERAIS, 2015).

A instrução inicia-se com a autuação do processo. Conforme o Decreto Estadual de $n^{\circ}$ 47.222, de 26 de julho de 2017 (MINAS GERAIS, 2017), que regulamenta a Lei $n^{\circ}$ 14.184, de 31 de janeiro de 2002 (MINAS GERAIS, 2002), dar-se o desenvolvimento do PAR no meio eletrônico.

Essa autuação conterá todos os indícios e provas já produzidas que, em tese, são considerados como atos lesivos à Administração Pública Estadual. Todavia, não está impedida a Comissão de realizar diligências necessárias, com imparcialidade e independência, de acordo com os artigos $8^{\circ}$ e $9^{\circ}$ do Decreto Estadual de $n^{\circ} 46782 / 15$ (MINAS GERAIS, 2015).

Seguindo o andamento do feito, será providenciada a notificação à pessoa jurídica, contendo as informações elencadas nos incisos I a VIII do $\S 1^{\circ}$ do art. 10 do Decreto Estadual de n 46.782/15 (MINAS GERAIS, 2015). Caso não seja efetivada, será a notificação publicada na Imprensa Oficial de Minas Gerais. Em ambos os casos, a pessoa jurídica terá o prazo de trinta dias para se defender, quando poderá apresentar todas as provas admitidas em Juízo, sendo-Ihe facultada a sua defesa técnica, segundo os artigos 10 e 11 do Decreto Estadual de $n^{\circ}$ 46.782/15 (MINAS GERAIS, 2015).

A Comissão avaliará, de maneira fundamentada, o pedido quanto à produção de provas, estipulando prazo para tanto. As testemunhas de defesa apresentadas pela pessoa jurídica deverão comparecer independente de intimações e sob pena de preclusão, em audiências a serem designadas pela Comissão. Poderá a Comissão rejeitar fundamentadamente provas ilícitas, protelatórias, impertinentes, desnecessárias e intempestivas. Ademais, havendo juntada de novos documentos, abrir-se vista para a manifestação da pessoa jurídica em cinco dias, consoante os artigos 11 a 15 do Decreto Estadual de n 46.782/15. (MINAS GERAIS, 2015).

Encerrada a fase da instrução, a Comissão emitirá o Relatório Preliminar contendo os requisitos de I a VI do art. 16 do Decreto Estadual de n² 46782/15 (MINAS GERAIS, 2015).

A análise de "[...] informações e documentos referentes à existência e ao funcionamento de programa de integridade [...]" apresentados em defesa serão verificados pela Comissão nos critérios do Capítulo IV da Lei Federal de n 12.846/2013 (BRASIL, 2013), que trata da responsabilização judicial, "[...] para a dosimetria das sanções a serem aplicadas" e havendo fatos passíveis de serem apurados em sede de PAD, serão inseridos os fatos no relatório preliminar, de acordo com os parágrafos $1^{\circ}$ e $2^{\circ}$ do art. 16 do Decreto Estadual de n 46782/15 (MINAS GERAIS, 2015).

Antes de elaborar o relatório final, a Comissão intimará a pessoa jurídica para apresentar as suas alegações finais no prazo de dez dias, conforme o art. 17 do Decreto Estadual de $n^{\circ} 46782 / 15^{20}$ (MINAS GERAIS, 2015). A comissão terá o prazo de cento e oitenta dias para

20 Artigo com redação dada pelo art. $9^{\circ}$ do Decreto $n^{\circ} 47.752$, de 12/11/2019, em vigor a partir de 12/12/2019. Antes da alteração, no art. 19 prescrevia que: "Antes de decidir o processo, o Controlador-Geral do Estado intimará a pessoa jurídica para apresentar alegações finais no prazo de dez dias". Isto quer dizer que a AGE/MG se manifestaria e consecutivamente a pessoa jurídica, antes da decisão do Controlador-Geral do Estado de Minas Gerais (MINAS GERAIS, 2020). 
emitir o relatório final, de acordo com o parágrafo único do art. 17 do Decreto Estadual de ${ }^{\circ}$ 46782/15 (MINAS GERAIS, 2015).

Depois, o processo será encaminhado à Advocacia-Geral do Estado de Minas Gerais para manifestação no prazo de vinte dias, podendo ser prorrogado pelo mesmo período, de acordo com a complexidade da apuração. Da análise da AGE/MG, os autos serão encaminhados diretamente por essa Entidade ao Controlador-Geral, para julgamento, tendo em vista o art. 17-A do Decreto Estadual de n² 46782/15 (MINAS GERAIS, 2015).

De acordo com os fatos e fundamentos, a decisão será emitida em trinta dias, podendo ser prorrogada considerando a complexidade do assunto, no caso concreto. Sendo a decisão condenatória, o corpo do extrato de solução a ser publicado deverá conter, entre outros elementos, o nome do órgão ou entidade, o nome ou razão social da pessoa jurídica, o seu respectivo número no CNPJ e o resumo das infrações praticadas nos termos da Lei Federal n 12.846, de 2013, apresentando os dispositivos legais cabíveis (BRASIL, 2013).

Da decisão, poderá ser acatado pelo Controlador-Geral o relatório conclusivo da comissão, sendo que, se contrário às provas nos autos, poderá agravar a penalidade, diminui-la ou isentar a pessoa jurídica da responsabilidade. Ainda, poderá arquivar os autos desde que demonstrado em relatório conclusivo a inexistência de prática de infração pela pessoa jurídica. Havendo vício insanável, total ou parcial, devolverá os autos e designará outra comissão. 0 julgamento fora do prazo não gera nulidade, todos esses comandos estão contidos nos artigos 20 a 23 do Decreto Estadual de $n^{\circ}$ 46782/15 (MINAS GERAIS, 2015).

A pessoa jurídica será intimada da decisão, podendo recorrer no prazo de dez dias. Caso o Controlador-Geral não reconsidere a decisão, os autos serão direcionados à Junta de Recursos de Processos Administrativos de Responsabilização - JRPAR ${ }^{21}$, para apreciação e decisão, sendo um órgão colegiado instituído para apreciar esse julgamento específico, de acordo com os artigos 24 a 29, todos do Decreto Estadual de n 46782/15 (MINAS GERAIS, 2015).

No art. 27 do Decreto Estadual de n 46782/15 reza sobre a desconsideração da pessoa jurídica. Isto acontece quando, antes da emissão do relatório final, a Comissão constata

21 Art. 26, §1: "A JRPAR é composta pelos seguintes membros:

I - Advogado-Geral do Estado, que a preside;

II - Consultor-Geral de Técnica Legislativa;

III - Secretário de Estado de Fazenda;

IV - Secretário de Estado de Governo;

V - Secretário de Estado de Planejamento e Gestão.

$\S 2^{\circ}$ - A AGE prestará apoio administrativo para o funcionamento da JRPAR.

$\S 3^{\circ}-0$ Advogado-Geral do Estado, ou procurador por ele delegado, agendará e presidirá as sessões da JRPAR.

$\S 4^{\circ}-$ Nas sessões de julgamento previamente agendadas, os titulares de que trata o $\S 1^{\circ}$ poderão delegar, de forma justificada, a servidor de seu órgão, a competência para proferir o voto sobre questões preliminares e de mérito.

$\S 5^{\circ}$ - Os julgamentos serão públicos e feitos em sessão ordinária ou extraordinária, observada a seguinte ordem de trabalho:

I - verificação do número de titulares presentes e, se houver quórum de maioria absoluta, abertura de sessão;

II - julgamento dos processos incluídos em pauta pelo voto da maioria dos presentes;

III - apresentação de indicações e propostas;

IV - conferência e assinatura de acórdãos.

$\S 6^{\circ}-0$ Advogado-Geral do Estado somente votará em caso de empate.

$\S 7^{\circ}-0$ recurso terá efeito suspensivo e deverá ser julgado no prazo de trinta dias, prorrogável por igual período, conforme a complexidade da causa e as demais características do caso concreto.

$\S 8^{\circ}$ - Encerrado o PAR, a decisão final será publicada no Diário Oficial Eletrônico Minas Gerais, dando-se conhecimento de seu teor ao Ministério Público para apuração de eventuais ilícitos, inclusive quanto à responsabilidade individual dos dirigentes da pessoa jurídica ou seus administradores ou de qualquer pessoa natural, autora, coautora ou partícipe." (MINAS GERAIS, 2015) 
que os sócios administradores ou aqueles com poderes de administração agiram conforme o artigo 14 da Lei Federal de $n^{\circ} 12.846 / 13$, ou seja, com "[...] abuso do direito para facilitar, encobrir ou dissimular a prática dos atos ilícitos previstos nesta Lei ou para provocar confusão patrimonial [...]", serão citados e cientificados que aos mesmos poderão ser "[...] estendidos os efeitos das sanções aplicadas à pessoa jurídica [...], observados o contraditório e a ampla defesa."(MINAS GERAIS, 2015).

Tal inclusão dos sócios administradores ou aqueles com poderes de administração no polo passivo também poderá ser solicitada pelo Controlador-Geral. Terão o mesmo prazo legal de defesa da pessoa jurídica e da decisão sobre a desconsideração da pessoa jurídica cabe recurso nos termos do artigo 20 do Estadual de $n^{\circ}$ 46782/15 (MINAS GERAIS, 2015).

Nos artigos 28 a 38 do Decreto Estadual de n 46782/15 dispõem sobre "simulação ou fraude na fusão ou incorporação" (MINAS GERAIS, 2015). Considerando a importância do tema, havendo indícios nos termos do $\S 1^{\circ}$ do art. $4^{\circ}$ da Lei Federal de $n^{\circ}$ 12.846/13 (BRASIL, 2013), a Comissão poderá inserir tal constatação no relatório conclusivo, porém deve-se observar os princípios da ampla defesa e do contraditório, sendo objeto também de recurso.

Ainda, no Decreto em análise dispõe sobre mecanismos e procedimentos internos (da pessoa jurídica) de integridade e acordo de leniência, conforme os artigos 39 a 49 do Decreto Estadual de $n^{\circ} 46782 / 15^{22}$ (MINAS GERAIS, 2015). Esses mecanismos e procedimentos foram instituídos pela Medida Provisória de n 703/2015 (BRASIL, 2015), com vigência encerrada, porém continua com a sua aplicação vigente, tendo em vista o Decreto Estadual de $n^{\circ}$ 46.782/15, no seu art. $40^{23}$ (MINAS GERAIS, 2015) e inciso III do art. $7^{\circ}$ da Resolução Conjunta CGE/AGE n 4, de 12 de novembro de 2019 (MINAS GERAIS, 2019).

22 "Art. 39. Para fins do disposto neste Decreto, programa de integridade consiste, no âmbito de uma pessoa jurídica, no conjunto de mecanismos e procedimentos internos de integridade, auditoria e incentivo à denúncia de irregularidades e na aplicação efetiva de códigos de ética e de conduta, políticas e diretrizes com o objetivo de detectar e sanar desvios, fraudes, irregularidades e atos ilícitos praticados contra a administração pública, nacional ou estrangeira.

Parágrafo único. O programa de integridade deve ser estruturado, aplicado e atualizado de acordo com as características e riscos atuais das atividades de cada pessoa jurídica, a qual por sua vez, deve garantir o constante aprimoramento e a adaptação do referido programa, visando a garantir sua efetividade". (MINAS GERAIS, 2015)

23 "Art. 40: I- comprometimento da alta direção da pessoa jurídica, incluídos os conselhos, evidenciado pelo apoio visível e inequívoco ao programa;

II - padrões de conduta, código de ética, políticas e procedimentos de integridade, aplicáveis a todos os empregados e administradores, independentemente de cargo ou função exercidos;

III - padrões de conduta, código de ética e políticas de integridade estendidas, quando necessário, a terceiros, tais como, fornecedores, prestadores de serviço, agentes intermediários e associados;

IV - treinamentos periódicos sobre o programa de integridade;

$\mathrm{V}$ - análise periódica de riscos para realizar adaptações necessárias ao programa de integridade;

$\mathrm{VI}$ - registros contábeis que reflitam de forma completa e precisa as transações da pessoa jurídica;

$\mathrm{VII}$ - controles internos que assegurem a pronta elaboração e confiabilidade de relatórios e demonstrações financeiros da pessoa jurídica;

VIII - procedimentos específicos para prevenir fraudes e ilícitos no âmbito de processos licitatórios, na execução de contratos administrativos ou em qualquer interação com o setor público, ainda que intermediada por terceiros, tal como pagamento de tributos, sujeição a fiscalizações, ou obtenção de autorizações, licenças, permissões e certidões;

IX - independência, estrutura e autoridade da instância interna responsável pela aplicação do programa de integridade e fiscalização de seu cumprimento;

$\mathrm{X}$ - canais de denúncia de irregularidades, abertos e amplamente divulgados a funcionários e terceiros, e de mecanismos destinados à proteção de denunciantes de boa-fé;

XI - medidas disciplinares em caso de violação do programa de integridade;

XII - procedimentos que assegurem a pronta interrupção de irregularidades ou infrações detectadas e a tempestiva remediação dos danos gerados;

XIII - diligências apropriadas para contratação e, conforme o caso, supervisão, de terceiros, tais como, fornecedores, prestadores de serviço, agentes intermediários e associados; 
Tanto os mecanismos e procedimentos de integridade, quanto o acordo de leniência, serão considerados no momento da aplicação da sanção, conforme o tópico a frente a ser desenvolvido.

A AGE/MG atuará nos acordos de leniência ${ }^{24}$, na fase dos processos de negociação, celebração e acompanhamento deste, conforme a Resolução Conjunta CGE/AGE n 4, de 12 de novembro de 2019. (MINAS GERAIS, 2019)

A desistência ou a rejeição pela pessoa jurídica da proposta do acordo não implicará em reconhecimento do exercício do ato lesivo e os documentos serão devolvidos, de acordo com os incisos I e II do parágrafo único do art. 10 da mencionada Resolução Conjunta (MINAS GERAIS, 2019).

Depois de formalizado, pode-se se tornar público o acordo de leniência, exceto nas "[...] hipóteses legais de sigilo, que devem ser observadas por aqueles que tenham acesso aos elementos de prova por força das atividades de alavancagem investigativa ou outra atuação decorrente dos acordos de leniência". A comissão de negociação será formalizada em Portaria Conjunta entre CGE/AGE, tendo dois Auditores estáveis e um Procurador do Estado. (§2 do art. $4^{\circ}$ e $5^{\circ}$, ambos da Resolução Conjunta CGE/AGE nº 4/2019) (MINAS GERAIS, 2019).

De acordo com o inciso II do art. $7^{\circ}$ da citada Resolução, a Comissão deverá avaliar se a pessoa jurídica irá "[...] cooperar com a apuração de ato lesivo específico, quando tal circunstância for relevante, obedecida a ordem de prioridade cronológica das manifestações; b) admite sua participação na infração administrativa". Ainda, se "[...] compromete a cessar completamente seu envolvimento no ato lesivo", bem como contribuir com as investigações e o processo administrativo, identificando "[...] agentes públicos, empregados e particulares envolvidos na infração administrativa" (MINAS GERAIS, 2019).

Haverá cláusula no acordo de leniência que exigirá da pessoa jurídica colaboração numa solução eficaz do processo; realizar mudanças que visem a acabar ou diminuir a ocorrência de novos atos lesivos; em criar ou melhorar seu programa de integridade; o acompanhamento das obrigações firmadas nesse acordo de leniência; e, por fim, a reparação do dano ou a não exigência de fazê-lo, de acordo com o inciso $V$ do art. $7^{\circ}$ da Resolução Conjunta CGE/ AGE n 4/2019 (MINAS GERAIS, 2019).

Por fim, em caso de descumprimento do acordo, a pessoa jurídica perderá seus benefícios e ficará três anos impedida de realizar novo acordo com a Administração Pública. Ademais, terá o vencimento antecipado de suas parcelas concernentes ao dano e enriquecimento ilícito, com a aplicação de multa atualizada, descontando as frações que possam já estar quitadas, sendo o descumprimento registrado no Cadastro Nacional de Empresas Punidas - CNEP pela CGE, segundo o art. 10 da mencionada Resolução Conjunta (MINAS GERAIS, 2019).

XV - monitoramento contínuo do programa de integridade, visando ao seu aperfeiçoamento na prevenção, detecção e combate à ocorrência dos atos lesivos previstos no art. $5^{\circ}$ da Lei $n^{\circ} 12.846$, de 2013; e XVI - transparência da pessoa jurídica quanto às doações para candidatos e partidos políticos. (MINAS GERAIS, 2015)

24 "Art. $2^{\circ} \mathrm{O}$ acordo de leniência será celebrado com as pessoas jurídicas responsáveis pela prática dos atos lesivos previstos na Lei Federal $n^{\circ} 12.846$, de $1^{\circ}$ de agosto de 2013, e dos ilícitos administrativos previstos na Lei Federal $n^{\circ} 8.429$, de 2 de junho de 1992, na Lei Federal n 8.666, de 21 de junho de 1993, e em outras normas de licitações e contratos, com vistas à isenção ou à atenuação das respectivas sanções, desde que colaborem efetivamente com as investigações e com o processo administrativo, devendo resultar dessa colaboração: I - a identificação dos demais envolvidos no ato ilícito, quando houver; e II - a obtenção célere de dados, informações e documentos que comprovem o ilícito sob apuração". Dispositivo de acordo com a RESOLUÇÃO CONJUNTA CGE/AGE N 4, DE 12 DE NOVEMBRO DE 2019. (MINAS GERAIS, 2019) 
A sanção quanto à responsabilidade administrativa da pessoa jurídica ocorre por meio da multa e publicação extraordinária da decisão condenatória ${ }^{25}$. Estão citadas art. $6^{\circ}$ da Lei Federal de no 12.846/13 (BRASIL, 2013), bem como no art. 29 do Decreto Estadual de $n^{\circ}$ 46.782/15 (MINAS GERAIS, 2015).

A aplicação da multa será avaliada através dos requisitos contidos no art. $7^{\circ}$ da Lei Federal de $n^{\circ} 12.846 / 13$. São eles:

"I- a gravidade da infração; II - a vantagem auferida ou pretendida pelo infrator; III - a consumação ou não da infração; IV - o grau de lesão ou perigo de lesão; V - o efeito negativo produzido pela infração; VI - a situação econômica do infrator; VII - a cooperação da pessoa jurídica para a apuração das infrações; VIII - a existência de mecanismos e procedimentos internos de integridade, auditoria e incentivo à denúncia de irregularidades e a aplicação efetiva de códigos de ética e de conduta no âmbito da pessoa jurídica; IX - o valor dos contratos mantidos pela pessoa jurídica com o órgão ou entidade pública lesados; [...]" (BRASIL, 2013)

A gravidade da ação é destacável devido ao seu caráter sistêmico, ou seja, os efeitos nefastos que os atos corruptivos têm no Poder Público, quando acabam por envolver níveis da administração pública e a pessoa jurídica.

A vantagem auferida deve ser provada, por registro manual ou e-mail, ou até mesmo por confissão, tendo em vista que é inconcebível a sua imputação intuitiva, pois a responsabilidade a ser recaída sob a pessoa jurídica é a objetiva e o "quantum" ambicionado deve estar devidamente comprovado.

Como já foi estudado, não existe a tentativa nos casos arrolados no art. $5^{\circ}$ da Lei Federal de $n^{\circ}$ 12.846/13 (BRASIL, 2013). Todavia, a graduação da sanção vai variar dependendo do estágio do ato em que se encontrar. Por exemplo, uma promessa de pagamento por ato ilícito futuro. $\mathrm{O}$ ato em si já se consumou, porém tem-se a mera combinação; o efetivo pagamento e a obtenção do favor. No momento da aplicação da sanção se avaliará em qual fase se encontrava o ato lesivo passível de pena. $O$ ato já se consumou com a combinação, sendo os demais procedimentos são exaurimentos, dando a conotação das causas de graduação da sanção. A não consumação pode ensejar causa atenuante, dependendo do entendimento da autoridade que irá decidir.

O grau de lesão ${ }^{26}$ (ou perigo) é o bem público lesado, como, por exemplo, no caso da área da saúde, quando em plena pandemia, um produto considerado essencial, que serviria no controle de doenças e mortes, tendo o seu uso impedido ou desvirtuado, isto ensejaria um grau de lesão ou perigo bem elevado.

25 Sanção administrativa: 1) Multa: 0,1 a 20\% do faturamento bruto do último exercício anterior a instauração do PAR, excluídos os tributos (art. $6^{\circ}$, inciso I) ou de $R \$ 6.000,00$ a R\$ 60.000.000,00 (art. $6^{\circ}, \S^{\circ}$ ); e 2) Publicação extraordinária da decisão condenatória, de acordo com art. $6^{\circ}$. Disposições contidas na Lei Federal de $n^{\circ} 12.846 / 13$ inciso II da Lei Federal de $n^{\circ}$ 12.846/13. (BRASIL, 2013)

As sanções civis (art. $6^{\circ}$, II, da Lei Federal de $n^{\circ} 12.846 / 13$ ): "I - perdimento dos bens, direitos ou valores que representem vantagem ou proveito direta ou indiretamente obtidos da infração, ressalvado o direito do lesado ou de terceiro de boa-fé; II - suspensão ou interdição parcial de suas atividades; III - dissolução compulsória da pessoa jurídica; IV - proibição de receber incentivos, subsídios, subvenções, doações ou empréstimos de órgãos ou entidades públicas e de instituições financeiras públicas ou controladas pelo poder público, pelo prazo mínimo de 1 (um) e máximo de 5 (cinco) anos." (BRASIL, 213)

26 "Em outras palavras, a mensuração da lesão depende do grau de prejuízo ocasionado ao bem público atingido."(SOUZA, 2018. p.11) 
Considerando o efeito negativo da infração, esclarecem José Anacleto Abduch Santos, Mateus Bertoncini e Ubirajara Custódio Filho:

Os efeitos negativos podem ser relacionados a uma dimensão imaterial, como a perda ou abalo da credibilidade das instituições, ou a uma dimensão material, como interrupção da continuidade de serviços públicos ou de atividades públicas, prejuízos diretos ou indiretos para comunidades beneficiárias de políticas públicas, aumento de custos da atuação administrativa ou retardo na implementação de ações administrativas. (SANTOS, BERTONCINI e CUSTÓDIO FILHO, 2014, p.184)

Quanto a questão econômica do infrator, este dado é de grande importância porque a multa não deve aparentar irrisória e não tão alta que pudesse ter o caráter de confisco, procurando preservar a função social da pessoa jurídica, considerando os empregos gerados, fonte de pagamento de tributos, e até mesmo como fator de desenvolvimento cultural e econômico da região onde a pessoa jurídica se situa. Neste sentido, a multa não tem o condão de ensejar a "quebra" da pessoa jurídica ou a sua insolvência.

A cooperação da pessoa jurídica na apuração das infrações acontece independente do acordo de leniência, sendo necessário que esta se manifeste primeiramente o seu interesse em cooperar. Neste entendimento, a cooperação pode influenciar na dosimetria da multa.

No caso do acordo de leniência, de acordo com o inciso II do art. $6^{\circ}$ da Lei Federal de $\mathrm{n}^{\circ}$ 12.846/13 (BRASIL, 2013) poderá ensejar isenção da publicação da condenação ou a redução de um a dois terços da multa aplicável e, de acordo com o inciso VIII do art. 47 do Decreto Estadual de $n^{\circ}$ 46.782/15 (MINAS GERAIS, 2015) e art. 17 da Lei Federal de $n^{\circ} 12.846 / 13$, “[...] isentará ou atenuará as sanções administrativas estabelecidas nos arts. 86 a 88 da Lei $n^{\circ}$ 8.666, de 21 de junho de 1993" (MINAS GERAIS, 2013). Se o acordo de leniência for proposto após a instauração do PAR, a redução será de no máximo de um terço, conforme o $\S^{\circ}$ do art. 47 do Decreto Estadual de $n^{\circ}$ 46782/15. (MINAS GERAIS, 2015)

Em ambos os casos, a multa, se cabível, deverá ser paga em trinta dias e o inadimplemento acarretará a inscrição em dívida ativa do Estado, "[...] com posterior registro no Cadastro Informativo de Inadimplência do Estado de Minas Gerais - CADIN-MG -, na forma do Decreto $\mathrm{n}^{\circ}$ 44.694, de 28 de dezembro de 2007", de acordo com art. 37 do Decreto Estadual de $n^{\circ} 46782 / 15$. (MINAS GERAIS, 2015)

No caso de desconsideração da pessoa jurídica, os sócios administradores e administradores estarão também ao lado passivo, junto da pessoa jurídica, como devedores no título de dívida ativa.

A prescrição quanto a sanção a ser aplicada nessa matéria conta-se a partir de cinco anos das infrações, tendo por data inicial a ciência dos fatos, "[...] ou, no caso de infração permanente ou continuada, no dia em que tiver cessado", em consonância com o art. 25 da Lei Federal de $n^{\circ}$ 12. 846/13. (BRASIL, 2013)

Tanto na Lei Federal de $n^{\circ}$ 12846/13, artigos 22 a 29 (BRASIL, 2013), quanto no Decreto Estadual de $n^{\circ} 46782 / 15$, artigos 50 a 53 (MINAS GERAIS, 2015), dispõe do Cadastro Nacional de Empresas Punidas - CNEP, onde serão registradas as sanções aplicadas. 
Por fim, não impede a instauração, execução e aplicação de sanção decorrente de PAR ${ }^{27}$, mesmo se a pessoa jurídica já tiver penalidade em decorrência de Improbidade Administrativa, Lei Federal de $n^{\circ}$ 8.429/92 (BRASI, 1992) ; e atos ilícitos decorrentes da Lei Federal de $n^{\circ} 8.666 / 93^{28}$ (BRASIL, 1993), de acordo com a Lei Federal de $n^{\circ} 12846 / 13$, art. 30 (BRASIL, 2013), e Decreto Estadual de $n^{\circ} 46782 / 15$, art. 54. (MINAS GERAIS, 2015)

Verificando atos ilícitos decorrentes da ordem econômica, ou seja, que aviltem a defesa da concorrência, conforme a Lei Federal de n 12.529, de 30 de novembro de 2011, "[...]dará ciência ao Conselho Administrativo de Defesa Econômica - CADE - da instauração de PAR, podendo fornecer informações e provas obtidas, sem prejuízo do sigilo das propostas de acordo de leniência[...]" (BRASIL, 2011), segundo consta no art. 56 do Decreto Estadual de $n^{\circ} 46782 / 15$ (MINAS GERAIS, 2020) e no art. 16, $\S 6^{\circ}$, da Lei Federal n 12.846/13. (BRASIL, 2013).

\section{CONCLUSÃO}

A abordagem dos trâmites normativos dos processos administrativos correcionais, disciplinar e em desfavor de pessoa jurídica, são de suma importância, considerando a participação ativa de todos os sujeitos processuais, com vista a proporcionar um processo transparente e isonômico.

Seguindo esse entendimento, deve o servidor acusado, bem como a pessoa jurídica, estarem cientes das especificidades processuais, pois não podem alegar o desconhecimento das leis, bem como aquele que os defende, para uma melhor atuação técnica.

Portanto, mesmo com fins diferenciados, tais processos possuem conotação punitiva e possuem, cada qual, sua relevância na seara administrativa, com repercussão social, pois o funcionamento integral e positivo da máquina pública e a sua integração à sociedade, numa relação íntegra, fortalece o Estado e traz maior credibilidade à nação.

\section{REFERENCIAS}

ALVES, Léo da Silva. Processo Disciplinar. Passo a passo. 2 ed. Brasília: Brasília Jurídica, 2004.

ALVES, Léo da Silva. Direito disciplinar para concursos jurídicos: guia de controle da disciplina. 1 ed. São Paulo: EDIPRO, 2012.

BRASIL. Constituição da República Federativa do Brasil de 1988. Disponível em: http://www.planalto.gov.br/ccivil_03/constituicao/constituicao46.htm. Acesso em: 12 abr. 2020.

27 "Logo, para incidência do dispositivo de dosimetria é suficiente aferir a ocorrência no caso concreto da hipótese legal descrita como fator de cálculo da multa e, em seguida, para determinar seu percentual, dentro dos limites mínimo e máximo previstos, é necessário averiguar sua relevância, ou seja, em que grau a forma de conduta ou circunstância contribuiu para o sucesso, perpetuação, agravamento ou atenuação da prática ilícita." (SOUZA, 2018, p. 31)

28 Conforme determina o art.23 da Lei Federal n 12.846/13, deverá manter atualizado o Cadastro Nacional de Empresas Inidôneas e Suspensas - CEIS, "[...] de todas as esferas de governo [...] os dados relativos às sanções [...], nos termos dos arts. 87 e 88 da Lei n 8.666, de 21 de junho de 1993". (BRASIL, 2020) 
BRASIL. Lei Federal no 8.429, de 2 de junho de 1992. Disponível em: http://www.planalto.gov.br/ccivil_03/leis/ 18429.htm Acesso: 26 abr. 2020.

BRASIL. Lei Federal n 8.666, de 21 de junho de 1993. Disponível em: http://www.planalto.gov.br/ccivil_03/leis/ I8666cons.htm. Acesso: 31 mai. 2020.

BRASIL. Lei Federal no 9.784/99. Disponível em: http://www.planalto.gov.br/ccivil_03/Leis/L9784.htm. Acesso: 20 de mar. 2020.

BRASIL. Lei n 12.846, de 01 de agosto de 2013. Disponível em: http://www.planalto.gov.br/ccivil_03/_ato20112014/2013/lei/l12846.htm. Acesso: 31 mai. 2020.

BRASIL. Lei no 12.529, de 30 de novembro de 2011. Disponível em: http://www.planalto.gov.br/ccivil_03/_ato20112014/2011/lei/l12529.htm. Acesso: 06 mai. 2020.

BRASIL, Presidência da República. Medida Provisória de nº 703/2015. Disponível em: http://www.planalto.gov.br/ ccivil_03/_Ato2015-2018/2015/Mpv/mpv703.htm. Acesso em: 11 ago. 2020.

BERTONCINI, Mateus; CUSTÓDIO FILHO, Ubirajara; SANTOS, José Anacleto Abduch Santos. Comentários à Lei $n^{\circ}$ 12.846/2013: Lei Anticorrupção. São Paulo: Revista dos Tribunais, 2014.

CARVALHO FILHO, José dos Santos. Manual de Direito Administrativo. 17ed. Rio de Janeiro: Lumen Juris, 2007. COSTA, José Armando da. Teoria e prática do processo administrativo disciplinar. 4 ed. Brasília: Jurídica, 2004. COSTA, José Armando da. Direito Disciplinar. Temas substantivos e processuais. Belo Horizonte: Fórum, 2008.

DALLARI, Adilson Abreu; FERRAZ, Sérgio. Processo Administrativo. São Paulo: Malheiros Editores, 2001.

LEAL, André Cordeiro. Instrumentalidade do processo em crise. Belo Horizonte: Mandamentos, 2008.

LUZ, Egberto Maia. Sindicância e Processo Disciplinar. 1 ed. São Paulo: EDIPRO, 1999.

MINAS GERAIS. Constituição Estadual de Minas Gerais. Disponível em: https://www.almg.gov.br/consulte/legislacao/completa/completa-nova-min.html?tipo=CON\&num $=1989 \&$ comp $=\& a n o=1989 \&$ texto $=$ consolidado.Acesso em: 15 jun. 2020.

MINAS GERAIS. Decreto Estadual de $n^{0}$ 46.782, de 23 de junho de 2015. Disponível em: https://www.almg.gov. $\mathrm{br} /$ consulte/legislacao/completa/completa.html?tipo=DEC\&num=46782\&comp=\&ano=2015. Acesso em: 03 jul. 2020.

MINAS GERAIS. Decreto Estadual de $n^{\circ}$ 47752, de 12 de novembro de 2019. Disponível em: https://www.almg. gov.br/consulte/legislacao/completa/completa.html?tipo=DEC\&num=47752\&comp=\&ano=2019. Acesso em: 03 jul. 2020.

MINAS GERAIS. Decreto Estadual de n 47774, de 03 de dezembro de 2019. Disponível em: https://www.almg. gov.br/consulte/legislacao/completa/completa.html?tipo=DEC\&num=47774\&comp=\&ano=2019. Acesso em: 03 jul. 2020.

MINAS GERAIS. Lei Estadual de n 869/52. Disponível em: https://www.almg.gov.br/consulte/legislacao/completa/completa-nova-min.html?tipo=LEI\&num=869\&ano=1952. Acesso em: 25 abr. 2020.

MINAS GERAIS. Lei Estadual de $n^{\circ}$ 14.184/2002. Disponível em: https://www.almg.gov.br/consulte/legislacao/ completa/completa.html?tipo=LEI\&num=14184\&comp=\&ano=2002. Acesso em: 31 abr. 2020

MINAS GERAIS. Manual de Tomada de Contas Especial. Controladoria-Geral do Estado de Minas Gerais. Disponível em: http://cge.mg.gov.br/phocadownload/manuais_cartilhas/pdf/manual-de-tce.pdf. Acesso em: 09 mai. 2020.

MINAS GERAIS. Manual de Apuração de Ilícitos Administrativos. Controladoria-Geral do Estado de Minas Gerais. Disponível em: https://www.google.com/search?q=manual+de+atos+ilicitos+cge+mg\&oq=manua\&aqs=chrome. 1.69i57j69i59j35i39j0i433I2j69i65j69i60l2.3121j0j7\&sourceid=chrome\&ie=UTF-8 . Acesso em: 30 out. 2020.

MINAS GERAIS. RESOLUÇÃO CONJUNTA CGE/AGE N 4, DE 12 DE NOVEMBRO DE 2019. Disponível em: http:// www.age.mg.gov.br/images/stories/downloads/resolucoes/resolucoes_conjuntas/2019-resolucaoconjunta-4-cge-age.pdf. Acesso em: 11 jun. 2020. 
SOUZA, Helton José Almeida de. Dosimetria de Multa nos Processos Administrativos de Responsabilização de Pessoa Jurídica: interpretações dos parâmetros legais de aplicação do artigo 6º inciso I, da Lei n 12.846/13, na União, Estados e Municípios brasileiros. Curso de Pós-Graduação Lato Sensu em "Corrupção: Controle e Repressão a Desvios de Recursos Públicos" pela Sociedade de Ensino Superior Estácio de Sá Ltda. em parceria com o Complexo de Ensino Renato Saraiva - PÓS ESTÁCIO CERS, 2018.

Recebido/Received: 02.10.2020.

Aprovado/Approved: 19.12.2020. 